\title{
O DESIGN NO PROCESSO DE APRENDIZAGEM NA TERCEIRA IDADE: UM MAPEAMENTO PRELIMINAR DE PROBLEMAS ERGONÔMICOS NO AMBIENTE DE ENSINO - ESTUDO DE CASO NA UNIVERSIDADE DA TERCEIRA IDADE UNITI/UFMA
}

\author{
Andréa Katiane Ferreira Costa; Mestra \\ Universidade Federal do Maranhão \\ andrea.katianefc@gmail.com
}

Lívia Flávia de Albuquerque Campos; Doutora Universidade Federal do Maranhão liviaflavia@gmail.com

Bruno Serviliano Santos Farias; Mestre Universidade Federal do Maranhão brunoserviliano@gmail.com
Arthur José Silva Marques; Graduando Universidade Federal do Maranhão arthurgarre@gmail.com

Ana Luiza Lima Rodrigues; Graduando Universidade Federal do Maranhão analuizalimarodrigues@gmail.com

Raquel Gomes Noronha; Doutora Universidade Federal do Maranhão raquelnoronha79@gmail.com

Márcio James Soares Guimarães; Mestre Universidade Federal do Maranhão falecommg@gmail.com

Resumo: Este trabalho faz parte do Projeto de pesquisa "Mediação do design no processo de aprendizagem na terceira idade" desenvolvido pelo NIDA - Núcleo de Pesquisa em Imagem, Design e Antropologia do curso de Design, da UFMA - Universidade Federal do Maranhão. Este segmento da pesquisa se ocupa em analisar o ambiente de ensino da UNITI Universidade Integrada da Terceira Idade da UFMA. Assim, partimos da pesquisa etnográfica com observação das aulas, e entrevistas com docentes. Como conclusão a pesquisa aponta as barreiras, em especial na estrutura física do ambiente de ensino e propõem sugestões de melhorias a partir de método de intervenção ergonomizadora.

Palavras-chave: Ambiente de ensino, Design, Ergonomia, Terceira idade.

Abstract: This work is part of research project "Design Mediation in the learning process in old age" developed by NIDA - Research Center for Images, Design and Antropology, course design, UFMA - Federal University of Maranhão. This segment of the research is concerned with analyzing the learning environment of UNITI - Integrated University of the Third Age UFMA. So, we start from the ethnographic research with observation of lessons and interviews with teachers. As conclusion research indicates as barriers, especially in the physical structure of the learning environment and propose improvements suggestions Intervention method from ergonomizadora.

Keywords: Teaching environment, Design, Ergonomics, Senior Adult. 


\section{INTRODUÇÃO}

A UNITI é um ambiente de ensino onde são desenvolvidas ações educativas baseadas na promoção dos idosos. Tem como proposta a interatividade, compartilhamento de experiências e preparação para viver bem a velhice.

Estudos científicos sobre a velhice podem contribuir para atenuar as limitações próprias da idade, como o declínio das funções biológicas. Skinner e Vaughan (1985, p. 28 e 35) afirmam que nossos corpos mudam com o envelhecimento e nossos sentidos tornam-se menos precisos. Programas como a UNITI, tem importante papel para melhorar a qualidade de vida dos idosos, pois trabalham os aspectos físicos e psicológicos, uma vez que os discentes se sentem pertencentes a um grupo social, aceitando melhor o processo de envelhecimento.

O designer pode contribuir com os processos de aprendizagem na terceira idade promovendo melhorias no ambiente sob diversos aspectos, inclusive o físico, com adaptações, promoção de acessibilidade, melhorias do layout, conforto; no uso de tecnologias, gerando um ambiente pedagógico mais seguro e eficiente. Tais intervenções envolvem a investigação das barreiras de toda ordem e seus impactos.

O objetivo deste trabalho é realizar análise preliminar de aspectos físicos do ambiente de ensino, seus componentes e conforto, que contribui para a melhoria na qualidade de ensino dos alunos da UNITI. Considerando que tais aspectos influenciam no cognitivo como a questão dos ruídos que dificultam a concentração e o déficit de iluminação que reduz a produtividade, afetando o desempenho da aprendizagem.

\section{REFERENCIAL TEÓRICO}

\subsection{Ambiente de Ensino}

De acordo com Ferreira (2002), ambiente é "aquilo que cerca ou envolve os seres vivos ou as coisas. Conjunto de características gerais de um computador, sistema operacional, ou programa; configuração". Já ensino é "transmissão de conhecimento; instrução. Os métodos empregados no ensino". Então, o ambiente de ensino é o espaço onde se "cria possibilidades para a sua produção ou a sua construção". E nesse sentido Freire afirma que ensino não é transferência de conhecimento e apesar das diferenças entre docente e discente, um não é objeto do outro, pois "quem ensina aprende ao ensinar e quem aprende ensina ao aprender" (FREIRE, 1996, p. 22-23).

$\mathrm{O}$ autor supracitado defende o respeito aos saberes construídos socialmente em práticas comunitárias e com os quais as pessoas já chegam no ambiente de ensino. Referindo-se aos grupos populares com os quais trabalhava, ele dizia que como educador precisava fazer "a leitura do mundo" que precede a "leitura da palavra", e que "ensinar exige compreender que a educação é uma forma de intervenção no mundo". (FREIRE, 1996, p.81 e p.98). Já para Libâneo educação "é o conjunto das ações, processos, influências, estruturas, que intervêm no desenvolvimento humano dos indivíduos e grupos na sua relação ativa com o meio natural e social...." (apud, COSTA, 2011, p.51). As contribuições de Freire e Libâneo são oportunas, pois nos ajuda a perceber os idosos como parte da construção de um conhecimento que não se inicia ou se encerra no espaço institucional, nos muros da universidade, mas é validado por uma relação que se estabelece entre o saber teórico e empírico acumulados. 


\subsection{Terceira idade}

Segundo o Instituto Brasileiro de Geografia e Estatística - IBGE, o número de pessoas com mais de 60 anos, no Brasil cresceu 55\% em 10 anos. Esses dados sinalizam para novas demandas com vistas a melhorar a qualidade de vida dos idosos, como: mobilidade, acesso a informação, a serviços, autonomia e saúde preventiva.

Ao longo da vida o ser humano faz o exercício de superação de seus limites, estes são maiores na velhice, considerando problemas inerentes a idade. Nesse sentido, Baltes \& Baltes, 1990 (apud Lima e Coelho 2011, p.8) sugerem “atividades educacionais e motivacionais promovidas pela universidade aberta ${ }^{1}$, para que idosos possam lançar mão dessas estratégias adaptativas de forma eficaz". Proposta que coincide com as da UNITI, inserção em grupos sociais, fortalecimento da capacidade cognitiva, enfrentamento de perdas e procura por estilo de vida saudável. Vale ainda frisar o reconhecimento dos direitos dos idosos, normatizados legalmente, através da Política Nacional do Idoso (1994) e do Estatuto do Idoso (2003).

Skinner e Vaughan (1985, p. 111-112) alertam que a velhice traz consigo sentimento de desamparo, perda do controle sobre o próprio corpo, baixa acuidade visual e baixa audição. Trata-se de pessoas com mobilidade reduzida, ou seja, com alguma limitação devido a alterações em sua estrutura física, sensorial, orgânica ou mental, tanto de caráter definitivo como temporário (Lei no 10.098/ 2000). Essa redução de mobilidade ameaça o direito de "ir e vir" do cidadão idoso sempre que as barreiras de toda ordem se impõem e seu direito a acessibilidade é negado.

\subsection{Estrutura física e elementos do conforto}

De acordo com a lei 10.098/2000, art. 2ㅜㅡ, acessibilidade é a "possibilidade e condição de alcance para utilização, com segurança e autonomia, dos espaços, mobiliários e equipamentos urbanos, das edificações, dos transportes e dos sistemas e meios de comunicação, por pessoa portadora de deficiência ou com mobilidade reduzida" (BRASIL apud BUSTO ROMERO, p. 429).

Gomes estabelece uma classificação em três níveis enquanto metodologia do design para o planejamento, organização e harmonia dos ambientes: configuração física do ambiente, ou seja, a arquitetura e seu design; componentes físicos do ambiente, podendo ser objetos isolados ou conjunto e conforto ambiental, como sistema de iluminação, ventilação, térmico, acústico, eletrônicos, de comunicação, acabamento, tratamento de superfície, considerando entre outros especificações técnicas e de uso (Gomes Filho, 2003, p. 205-206).

O conforto térmico é a sensação que o organismo humano experimenta quando "perde para o ambiente, sem recorrer a nenhum mecanismo de termorregulação, o calor produzido pelo metabolismo compatível com sua atividade". (FROTA E SCHIFFER apud BUSTO ROMERO, p.629). Segundo lida, a zona de conforto térmico está delimitada entre 20 e e $24 \circ \mathrm{C}$, considerando umidade relativa de $40 \%$ a $60 \%$ e velocidade do ar moderada de $0,2 \mathrm{~m} / \mathrm{s}$. (lida, 1992, p. 236).

O conforto luminoso supõe conjunto de fatores em um dado ambiente afim de permitir o desenvolvimento de atividades com precisão visual, menor esforço, menor risco de acidente e de prejuízo à vista (LAMBERTS apud BUSTO ROMERO, 2009, p.584).

\footnotetext{
${ }^{1}$ É um programa que promove a integração, inserção por meio do ensino, no caso da 3a idade essa integração de gerações acontece de modo informal.

(www.alagoas24horas.com.br/955161/universidade-aberta-terceira)
} 
Na NBR 5413/92 pode-se consultar a tabela para avaliar o conforto lumínico para cada tipo de ambiente. Para pessoas com acuidade visual abaixo da média, com perdas em média de $25 \%$ da visão deve-se utilizar os maiores valores da norma (lida, 1992, p.253-263; GARROCHO in BUSTO ROMERO, 2009, p. 584-587). Geralmente os idosos.

\section{MÉTODO DA PESQUISA}

Este estudo utilizou o método de pesquisa de Intervenção Ergonomizadora proposta por Moraes e Mont'Alvão (2009, p. 79-143). Método que pode se dividir em etapas: 1) Apreciação ergonômica; 2) Diagnose Ergonômica; 3) Projetação Ergonômica; 4) Avaliação, validação e/ou testes ergonômicos; e 5) Detalhamento ergonômico e otimização. Mas, esta pesquisa compreende apenas a Apreciação ergonômica, abordagem possível, segundo Moraes e Mont'Alvão (2009). Trata-se de fase exploratória compreendendo o mapeamento dos problemas ergonômicos, a sistematização do sistema homem-tarefa-máquina e a problematização, a qual, inclui a delimitação dos problemas ergonômicos. Para isso realizou-se pesquisa etnográfica que se caracteriza pela inserção continuada em campo, dedicando atenção à observação de discursos e práticas dos sujeitos da pesquisa. As representações coletivas e o imaginário dos atores sociais envolvidos no processo corroboram a percepção do pesquisador e ajudam na interpretação de fatores mais pragmáticos, como os dados aqui apresentados. A observação aconteceu durante três semanas do mês de novembro, final do ano letivo de 2015. Depois foram realizadas entrevistas semiestruturadas com professores selecionados tendo como critério a disponibilidade.

\section{RESULTADOS}

\subsection{Apreciação Ergonômica}

\subsubsection{Descrição do ambiente}

A estrutura física dos ambientes da UNITI apresentam-se de forma descentralizada no campus da UFMA: no prédio do CEB Velho (ficam as disciplinas teóricas - Gerontologia, Nutrição, Lazer e Turismo e Concentração e Memória), no prédio de Educação Física-Núcleo de Esportes e longe do CEB Velho (são realizadas as atividades de Yoga e Movimentos e Ritmos) e no Prédio do Herbário (as aulas de Fitoterapia), ver figuras de 1 a 5. Das disciplinas disponibilizadas pela UNITI, nos propusemos a observar as práticas: Yoga, Movimentos e Ritmos, e as teóricas: Fitoterapia, Gerontologia, Nutrição, Lazer e Turismo e Concentração e Memória.
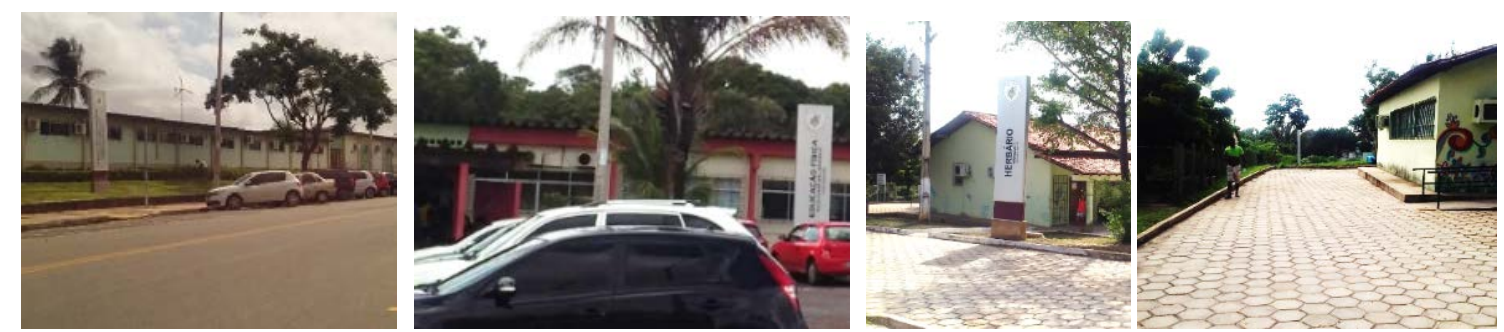

Figuras 1, 2, 3 e 4 - Fachada do CEB Velho, prédio do núcleo esportes, prédio do herbário/sala e horta Fonte: Acervo dos autores, São Luís, 2015

a) A Sala de Yoga no prédio de educação física, lâmpadas fluorescentes, aparelhos de ar condicionado, sete aparelhos de pilates ocupando centro da sala 
(Figuras 5 a 7). Alguns alunos chegam atrasados e ficam sem parede para execução de movimentos, pois uma das paredes está ocupada com matérias.
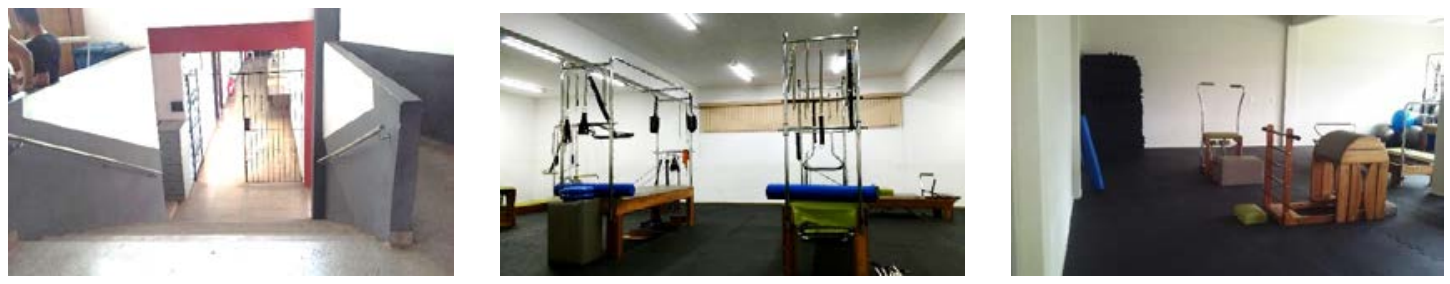

Figuras 5, 6 e 7 - acesso a sala de yoga, interior com alguns aparelhos.

Fonte: Acervo dos autores, São Luís, 2015

b) A Sala de Movimentos e Ritmos se torna estreita por ser ocupada com muitas cadeiras. $O$ espaço não é só de dança, acontecem aulas teóricas das disciplinas do curso de educação física (Figuras 8 a 10).
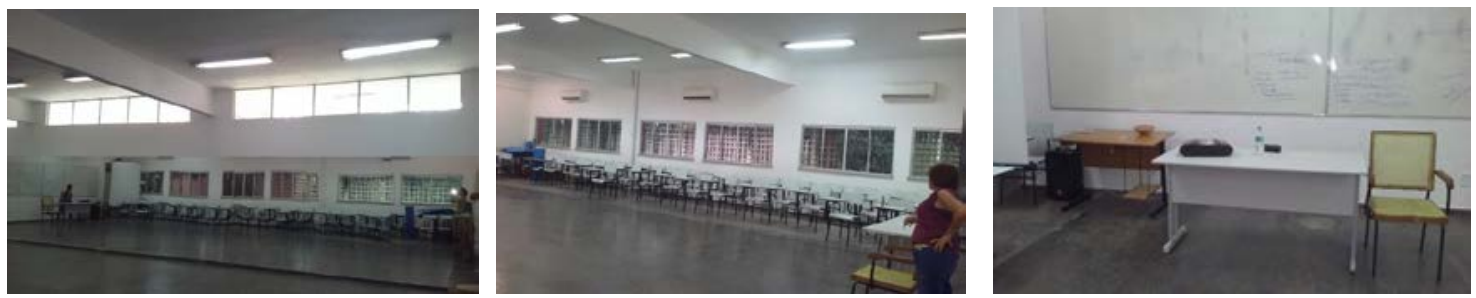

Figuras 8, 9 e 10 - sala de dança, espelho e componentes físicos Fonte: Acervo dos autores, São Luís, 2015

c) A maior parte das aulas teóricas - Gerontologia, Nutrição, Lazer e Turismo e Concentração e Memória-, são simultâneas, em três salas onde as professoras se revezam. Salas pequenas, climatizadas, lâmpadas fluorescentes, computador, Datashow, basculante, única porta de acesso, cadeiras ora dispostas em forma de " $U$ " e muito próximas da lousa, ora organizadas em filas, mas geralmente muitas empilhadas no fundo e sempre com excesso de alunos (Figuras 11 e 12).
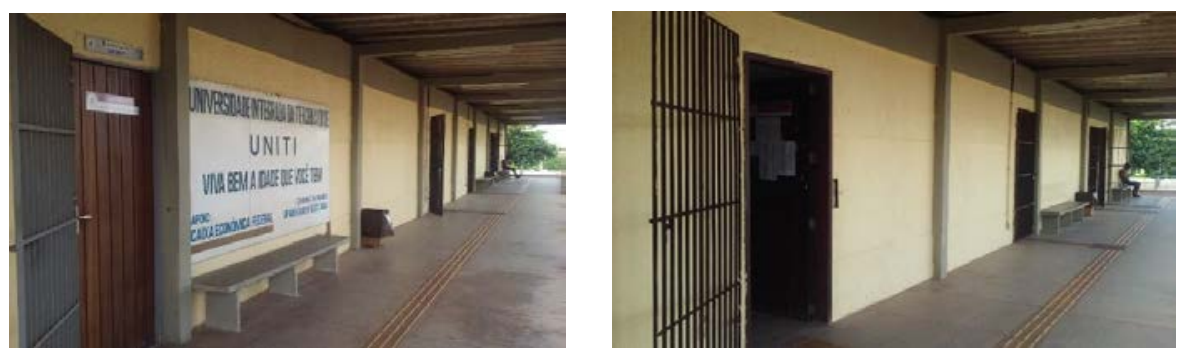

Figuras 11 e 12 - CEB Velho: área de acesso a coordenação da UNITI e as três salas de aulas teóricas.

Fonte: Acervo dos autores, São Luís, 2015

d) As aulas de Fitoterapia acontecem no prédio do Herbário e são complementadas na horta ao lado. Apesar de mais da metade das lâmpadas estarem queimadas, o ambiente não parece pouco iluminado. Tudo na sala possui aspecto antigo, aparelho de ar condicionado barulhento e sem manutenção, mesa e cadeiras de madeira maciça, desconfortáveis, pesadas e sem acolchoamento, organizadas em filas. Não há computador e Datashow (Figuras 13 a 15). 

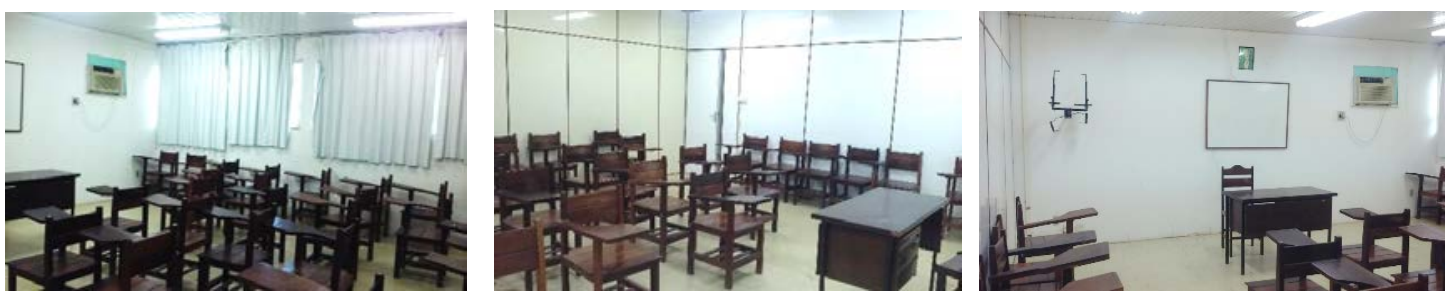

Figuras 13, 14 e 15 - sala de fitoterapia

Fonte: Acervo dos autores, São Luís, 2015.

\subsubsection{Caracterização do Sistema Homem-Tarefa-Máquina (SHTM)}

Segundo Moraes et al (1997, p.4) considerando o enfoque sistêmico, "deve-se inicialmente conhecer as características da máquina - o sistema em questão". Deve ser explicitado "o modelo do sistema operando: suas entradas ('inputs'), suas saídas ('outputs'), as atividades a serem desempenhadas pelo sistema". Assim, "a partir da modelagem da máquina que se propõe a construir, do que se pretende conseguir, pode-se então, elaborar o projeto de construção do sistema". Apresenta-se a seguir a caracterização do SHTM que apresenta o modelo do sistema operando (Figura 16).

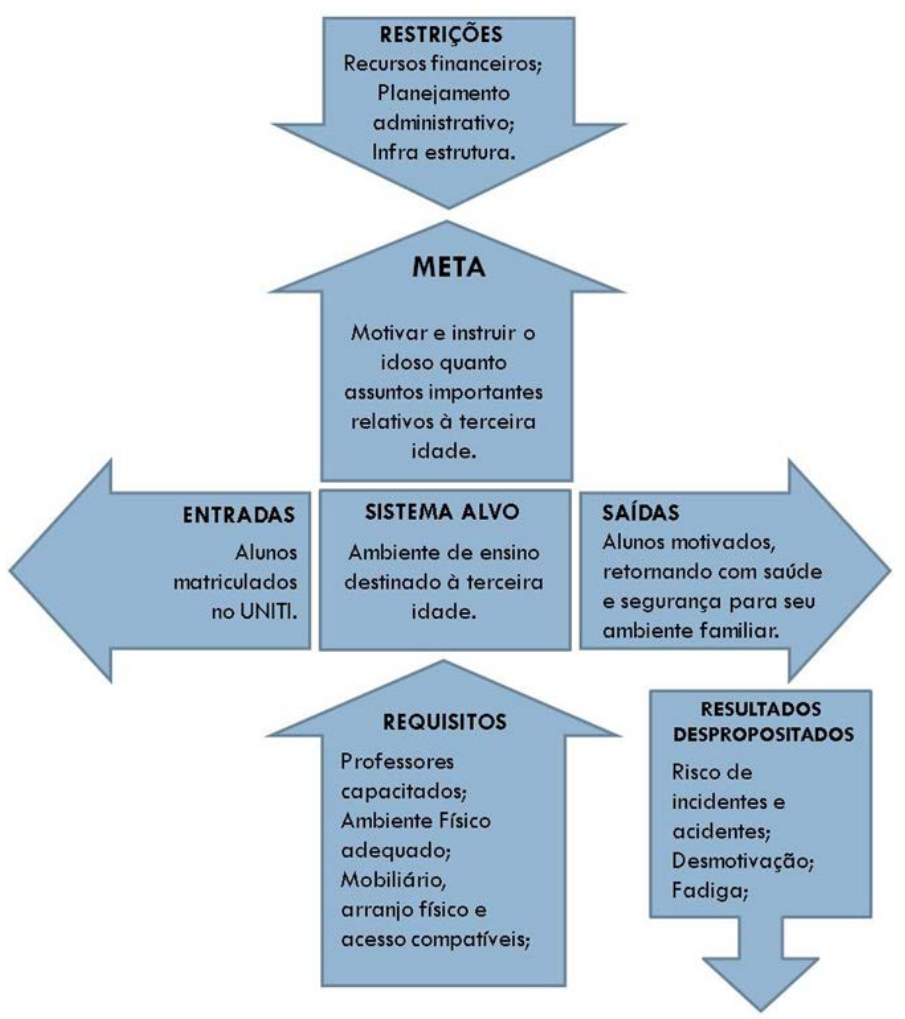

Figura 16 - Caracterização do SHTM

Fonte: Elaborado pelos autores, com base na pesquisa realizada

\subsubsection{Ordenação Hierárquica}

Segundo Moraes e Mont'Alvão (2009, p. 119 -120) a “Ordenação Hierárquica posiciona o sistema alvo conforme sua continência ou inclusão em outros sistemas hierarquicamente superiores. [...] Explicita os sistemas contidos no sistema alvo.

O sistema alvo estudado, "Ambiente de ensino destinado à terceira idade", está contido no Supra sistema UNITI - Universidade da Terceira Idade, que por sua vez está contida no Campus do Bacanga, seu supra supra sistema. Por fim a instituição que 
abriga, a UFMA - Universidade Federal do Maranhão que é o seu Ecossistema (Figura 17).

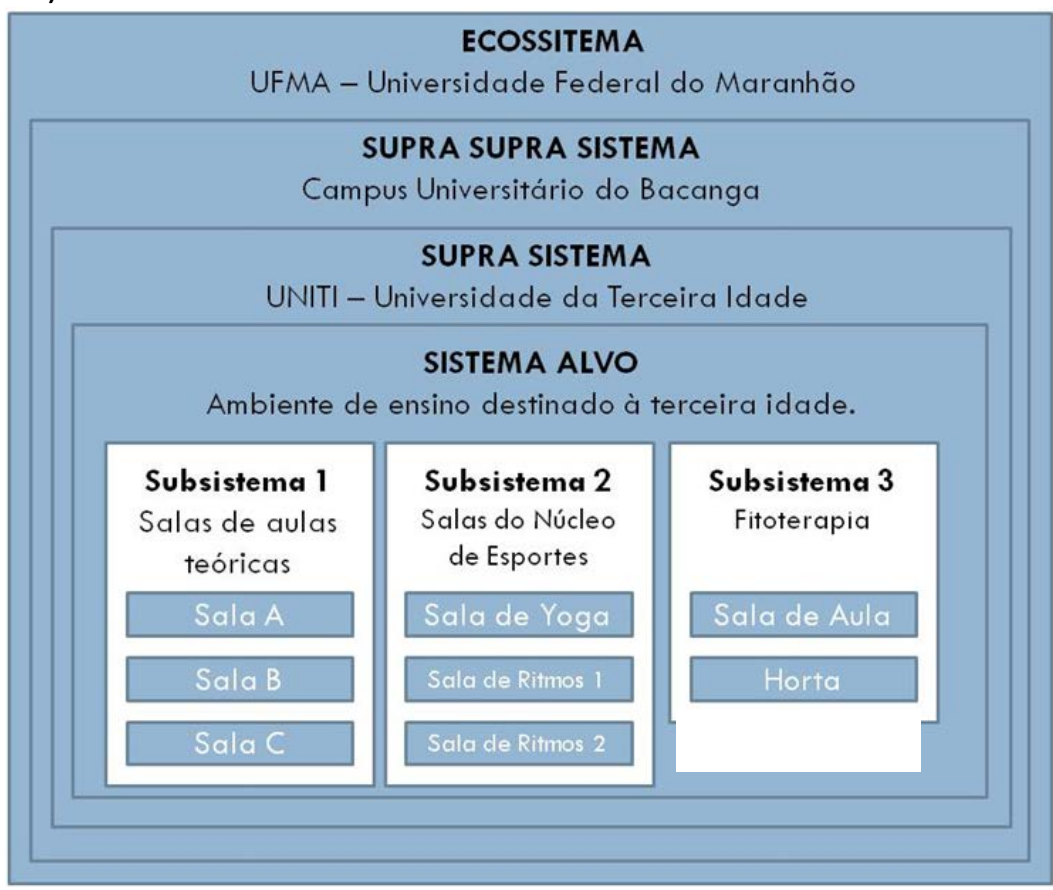

Figura 17 - Ordenação Hierárquica do sistema estudado - Fonte: do autor Fonte: Elaborado pelos autores, com base na pesquisa realizada.

Observa-se que o sistema alvo apresenta 3 (três) subsistemas. O Subsistema 1 é composto das salas de aula teóricas para as disciplinas de Gerontologia, Nutrição, Lazer e Turismo e Concentração e Memória. O Subsistema 2 é composto pelas salas disponibilizadas no Núcleo de Esportes do Campus do Bacanga, e o Subsistema 3 pelos espaços destinados às aulas de Fitoterapia no prédio do Herbário.

\subsubsection{Problematização}

A partir dos resultados das observações e entrevistas foram mapeados uma série de problemas os quais foram processados considerando a classificação da taxionomia de problemas proposta por Moraes e Mont'Alvão (2009). A taxionomia dos problemas está apresentada nos Quadros 1, 2 e 3 a seguir. 
Quadro 1 - Taxionomia dos problemas encontrados no ambiente de ensino da UNITI - Parte 1.

\begin{tabular}{|l|l|l|}
\hline PROBLEMAS & CARACTERIZAÇÃo & $\begin{array}{l}\text { DESCRIÇÃO DOS PROBLEMAS } \\
\text { ENCONTRADOS }\end{array}$ \\
\hline Movimentacionais & $\begin{array}{l}\text { Excesso de peso, distância do curso } \\
\text { da carga; Desrespeito aos limites } \\
\text { recomendados de movimentação } \\
\text { manual de cargas, com risco para o } \\
\text { sistema muscular e esquelético; }\end{array}$ & $\begin{array}{l}\text { Salas destinadas às aulas teóricas } \\
\text { apresentam um amontoado de cadeiras no } \\
\text { fundo, alunos que chegam atrasados } \\
\text { precisam pegar a cadeira no amontoado do } \\
\text { fundo da sala e reclamam do peso. }\end{array}$ \\
\hline Deslocamentos & $\begin{array}{l}\text { Excesso de caminhamentos ou } \\
\text { deambulações; Grandes distâncias a } \\
\text { serem percorridas para a realização } \\
\text { das atividades; }\end{array}$ & $\begin{array}{l}\text { Os idosos que saem da dança para as aulas } \\
\text { teóricas tem que fazê-lo com rapidez, } \\
\text { considerando distância entre os prédios e } \\
\text { dependência de coletivo para o } \\
\text { deslocamento. }\end{array}$ \\
\hline De acessibilidade & $\begin{array}{l}\text { Despreocupação com a } \\
\text { independência e a autonomia dos } \\
\text { usuários com deficiência, idosos e } \\
\text { crianças; Má acessibilidade, espaços } \\
\text { inadequados para movimentação de } \\
\text { cadeiras de rodas, falta de apoios } \\
\text { para utilização de equipamentos. }\end{array}$ & $\begin{array}{l}\text { Único acesso para sala de Yoga é por } \\
\text { escada, significa barreira para pessoas com } \\
\text { mobilidade reduzida. } \\
\text { na sala de Movimentos e Ritmos falta a } \\
\text { barra fixa de apoio, comum para salas com } \\
\text { atividade do tipo. Mas constatou-se a barra } \\
\text { móvel, mais difícil de manusear. }\end{array}$ \\
\hline
\end{tabular}

Fonte: Elaborado pelos autores, com base na pesquisa realizada.

Quadro 2 - Taxionomia dos problemas encontrados no ambiente de ensino da UNITI - Parte 2.

\begin{tabular}{|c|c|c|}
\hline PROBLEMAS & CARACTERIZAÇÃO & $\begin{array}{l}\text { DESCRIÇÃO DOS PROBLEMAS } \\
\text { ENCONTRADOS }\end{array}$ \\
\hline $\begin{array}{l}\text { Espaciais / } \\
\text { Arquiteturais } \\
\text { de Interiores }\end{array}$ & $\begin{array}{l}\text { Deficiência de fluxo, circulação, } \\
\text { isolamento, má aeração, insolação, } \\
\text { iluminação natural, isolamento } \\
\text { acústico, térmico, radioativo, em } \\
\text { função dos materiais de acabamento } \\
\text { empregados; Falta de otimização } \\
\text { luminosa, da cor, da ambiência gráfica, } \\
\text { do paisagismo. }\end{array}$ & $\begin{array}{l}\text { Sala de Movimentos e Ritmos se torna } \\
\text { pequena ocupada com cadeiras empilhadas } \\
\text { atrapalhando o desenvolvimento das aulas. } \\
\text { O espelho está fixado em sentido que deixa } \\
\text { a sala com pouca profundidade para } \\
\text { movimentos para trás dos alunos. } \\
\text { A sala de Yoga torna-se pequena com seu } \\
\text { centro ocupado por aparelhos de pilates, } \\
\text { configurando-se obstáculos e dificultando a } \\
\text { visibilidade entre professor alunos. }\end{array}$ \\
\hline $\begin{array}{l}\text { Físico } \\
\text { Ambientais }\end{array}$ & $\begin{array}{l}\text { Temperatura, ruído, iluminação, } \\
\text { vibração, radiação, acima ou abaixo dos } \\
\text { níveis recomendados; }\end{array}$ & $\begin{array}{l}\text { A sala de Fitoterapia, precisa de correção } \\
\text { quanto a iluminação já que dos seis pontos } \\
\text { de luz presentes, mais da metade das } \\
\text { lâmpadas encontram-se queimadas. } \\
\text { A iluminação nas salas de aulas teóricas não } \\
\text { acontece de forma homogênea, estando a } \\
\text { parte dos fundos melhor iluminada pela } \\
\text { junção da luz artificial e da luz natural. } \\
\text { Considerando o tipo de atividades } \\
\text { desenvolvidas nesses espaços como fixação } \\
\text { da visão e leitura, faz-se necessário uma } \\
\text { quantidade maior de iluminação. } \\
\text { Há aparelhos de ar-condicionado antigos e } \\
\text { sem manutenção que proporcionam ruído } \\
\text { no ambiente. }\end{array}$ \\
\hline
\end{tabular}


Quadro 3 - Taxionomia dos problemas encontrados no ambiente de ensino da UNITI - Parte 3.

\begin{tabular}{|c|c|c|}
\hline PROBLEMAS & CARACTERIZAÇÃO & DESCRIÇÃO DOS PROBLEMAS ENCONTRADOS \\
\hline Interfaciais & $\begin{array}{l}\text { Posturas prejudiciais resultante } \\
\text { de inadequações com prejuízo } \\
\text { para os sistemas muscular e } \\
\text { esquelético. }\end{array}$ & $\begin{array}{l}\text { As cadeiras da sala de Fitoterapia são de madeira } \\
\text { maciça e não possuem acolchoamento o que pode } \\
\text { causar fadiga, dores lombares e outros problemas } \\
\text { na coluna vertebral. Apesar destas observações } \\
\text { não houve relatos quanto ao desconforto de tais } \\
\text { cadeiras. }\end{array}$ \\
\hline Acidentários & $\begin{array}{l}\text { Comprometem os requisitos de } \\
\text { segurança; Falta de dispositivos } \\
\text { de proteção; Precariedade do } \\
\text { solo, andaimes, rampas e } \\
\text { escadas; } \\
\text { Manutenção insuficiente; } \\
\text { Deficiência de rotinas e } \\
\text { equipamentos para emergência } \\
\text { e incêndios. }\end{array}$ & $\begin{array}{l}\text { As salas de aulas teóricas apresentam um } \\
\text { amontoado de cadeiras no fundo das salas, } \\
\text { representando risco de acidente já que os alunos } \\
\text { que chegam atrasados precisam pegar a cadeira } \\
\text { no amontoado, podendo, desequilibrar, } \\
\text { ocasionando em quedas, lesões e ferimentos; } \\
\text { Na sala de Yoga nem sempre há como os alunos } \\
\text { se apoiarem na parede a fim de executarem os } \\
\text { movimentos. Alguns idosos se encostam em } \\
\text { algum aparelho do centro, podendo ocasionar em } \\
\text { algum acidente por desequilíbrio. }\end{array}$ \\
\hline Organizacionais & $\begin{array}{l}\text { Falta de objetivação, } \\
\text { responsabilidade, autonomia e } \\
\text { participação }\end{array}$ & $\begin{array}{l}\text { Alguns professores parecem ter alguma } \\
\text { dificuldade com o uso de ferramentas } \\
\text { tecnológicas utilizadas em sala de aula, sendo } \\
\text { portanto dependentes do suporte técnico } \\
\text { frequentemente. } \\
\text { Os idosos ora reclamam do calor, ora reclamam } \\
\text { do frio - como consequência de problemas de } \\
\text { saúde como reumatismo, artrose, entre outros. }\end{array}$ \\
\hline Cognitivos & $\begin{array}{l}\text { Dificuldade de decodificação, } \\
\text { aprendizagem e memorização; }\end{array}$ & $\begin{array}{l}\text { Na sala de Movimentos e Ritos o espelho é } \\
\text { ressaltado como bom auxiliador, mas os alunos se } \\
\text { atrapalham muitas vezes com a imagem refletida } \\
\text { durante execução de movimentos. }\end{array}$ \\
\hline
\end{tabular}

Fonte: Elaborado pelos autores, com base na pesquisa realizada.

\subsubsection{Parecer Ergonômico}

A fim de sintetizar os problemas observados apresenta-se o Parecer Ergonômico a partir da classificação do problema, seguido do problema propriamente dito, seus requisitos, constrangimentos da tarefa, custos humanos do trabalho, disfunções do sistema, sugestões preliminares de melhoria e restrições do sistema (Moraes e Mont'Alvão, 2009, p. 136-143).

Quanto a classe dos problemas foram identificados: os movimentacionais, os de deslocamentos, de acessibilidade, espaciais/arquiteturais de interiores, físicoambientais, interfaciais, acidentários, cognitivos e organizacionais.

Em problemas movimentacionais quando todas as cadeiras disponíveis já estão ocupadas, os alunos necessitam transportar as que encontram-se empilhadas no fundo da sala. O requisito e sugestão preliminar de melhoria é inserir um número de cadeiras compatível com o de alunos matriculados. O constrangimento da tarefa e custo humano do trabalho são o transporte manual de carga, a exigência de esforço muscular e equilíbrio. Quanto a disfunção do sistema pode acontecer cansaço e desestímulo. As restrições do sistema são organizacional e espacial. Grande distância 
para deslocamento das salas do núcleo de esportes para as aulas teóricas, fazendo-se necessário a utilização de meio de transporte, caracteriza-se como problema, considerando o curto intervalo de tempo entre uma aula e outra, tendo os idosos que fazê-lo com rapidez. Assim, requisitamos a redução dos deslocamentos excessivos, a fim de evitar constrangimentos da tarefa como o cansaço, os atrasos e estresse. Quanto ao custo humano do trabalho tem-se a resistência e capacidade cardiovascular. Como disfunção do sistema pode acontecer o cansaço e o desestímulo para as atividades. A sugestão preliminar de melhoria é evitar deslocamentos excessivos no mesmo dia; providenciar transporte adequado quando este deslocamento não puder ser evitado; ou concentrar atividades em um único prédio. As restrições do sistema são organizacional e financeira.

Na sala de yoga o único acesso se faz por meio de escada e falta a barra fixa de apoio na sala de movimentos e ritmos. O requisito é a adequação do espaço para os idosos, procurando evitar constrangimento da tarefa e o custo humano do trabalho, que são respectivamente a dificuldade de acesso e a exigência de esforço físico. Em disfunção do sistema pode haver constrangimento e desestímulo. Sugerimos de forma preliminar para melhorias a inclusão de rampas de acesso com inclinação e corrimão adequados e/ou outras soluções de acesso conforme NBR 9050 (ABNT, 2009); ou substituição da sala por outra acessível além da inclusão de barras de apoio. A restrição pode ser organizacional e financeira.

Problemas espaciais/arquiteturais de interiores como layout e disposição de equipamentos na sala de Yoga podem comprometer sua eficiência apesar do espaço. Requerendo estudo para verificação da adequação do layout, a fim de evitar constrangimento da tarefa como pouco espaço para execução de movimentos para trás e custos humanos do trabalho como atenção. O constrangimento é a disfunção do sistema. A sugestão preliminar de melhoria é a readequação do espaço para melhor utilização do ambiente. As restrições do sistema são organizacionais e/ou financeiras.

Problemas físicos-ambientais são iluminação deficiente nas salas de fitoterapia e aulas teóricas, considerando que na primeira $50 \%$ das lâmpadas estão queimadas e na segunda a iluminação não é uniforme; ruído provocado por aparelhos de ar condicionado antigos e sem manutenção. Como requisito a iluminação adequada para a realização das atividades e redução do nível de ruídos, evitando constrangimentos da tarefa como dificuldade para enxergar, dificuldade para ouvir e se concentrar. Os custos humanos do trabalho são exigência de esforço visual e de desgaste do aparelho auditivo. As disfunções do sistema são fadiga e cansaço visual. Sugestões preliminares de melhorias: adequação à normas NBR 5413 (ABNT, 1992) a qual indica iluminância máxima (500 lux) adequada às salas de aula quando a capacidade visual dos observadores está abaixo da média; providenciar manutenção ou troca de aparelhos de ar condicionado por modelos mais silenciosos. Restrições organizacional e financeira.

$\mathrm{Na}$ classe de problemas interfaciais tem-se na sala de Fitoterapia as cadeiras de madeira maciça que não possuem acolchoamento. O requisito é o assento adequado, evitando assim o constrangimento da tarefa que é a dificuldade para permanecer sentado por longos períodos. Nesse caso o custo humano do trabalho é o desconforto e as disfunções do sistema são a fadiga, dores lombares e outros problemas na coluna vertebral. Como sugestões preliminares de melhoria que providencie a substituição das cadeiras. Em lida (1992, p.139-142), lê-se que deve existir um assento adequado 
para cada função. Para este caso, tais cadeiras devem apresentar uma camada acolchoada no assento, revestimento capaz de dissipar o calor e umidade gerados pelo corpo. Devido a protuberância para trás na altura das nádegas e a curvatura da coluna vertebral deve existir um espaço vazio de 15 a $20 \mathrm{~cm}$ entre o assento e o encosto. As restrições do sistema nesse caso são organizacional e financeira.

Problemas Acidentários foram observados na sala de Yoga quando alguns idosos improvisam se encostando em aparelhos no centro da sala para executar movimentos. Como requisito a adequação do espaço aos idosos, evitando assim o constrangimento da tarefa que é a dificuldade em realizar alguns movimentos sem a estabilidade ideal. $\mathrm{O}$ custos humanos do trabalho é o risco de acidente devido à perda de equilíbrio, podendo proporcionar lesões e traumas por impacto. As disfunções do sistema podem ser quedas, lesões, traumas e ferimentos. A sugestão preliminar de melhoria é a inclusão de barras de apoio e apenas o número adequado de cadeiras considerando que a sala é de ritmos e dança. As restrições são de ordem organizacional e financeira.

Dos problemas cognitivos ressaltamos que alguns alunos se atrapalham com a imagem refletida no espelho durante a execução dos movimentos. O que requer a adequação à capacidade cognitiva/motora do idoso. O constrangimento da tarefa é a dificuldade em acompanhar a aula. E no custo humano do trabalho o embaraço, a perda de ritmo e o descompasso. A disfunção do sistema pode ser o constrangimento e desestímulo. Como sugestão preliminar de melhoria fica a verificação da readequação da estratégia de uso do espelho e na restrição do sistema o organizacional.

Em problemas organizacionais constatou-se que alguns professores têm alguma dificuldade com o uso de ferramentas tecnológicas utilizadas em sala de aula, sendo dependentes do suporte técnico frequentemente; também foi possível perceber que os idosos ora reclamam do calor, ora reclamam do frio - como consequência de problemas de saúde como reumatismo, artrose, entre outros. O que requer melhorar acesso à ferramentas tecnológicas de suporte ao ensino. Quanto ao constrangimento da tarefa e aos custos humanos do trabalho tem-se respectivamente a dificuldade em utilizar alguns equipamentos e o embaraço além do estresse. Em disfunções do sistema tem-se a perda de tempo, desestimulo, perda de foco e atenção. A sugestão de melhorias é o planejamento e efetuação de uma capacitação ou atualização para os docentes, a fim de promover autonomia no ambiente de ensino. A restrição é organizacional.

\section{CONSIDERAÇÕES FINAIS}

O trabalho de pesquisa junto a UNITI continua, entretanto nesta primeira etapa do processo já é possível perceber aspectos positivos e negativos no ambiente físico de ensino. Afim de contribuir para um ambiente mais seguro e adequado para o público da terceira idade, destacamos alguns problemas e sugerimos possíveis intervenções. Para tanto utilizou-se de pesquisa etnográfica com observações em sala de aula e entrevistas com os professores. E do método de pesquisa de Intervenção Ergonomizadora, e consequentemente dos resultados, com a apreciação onde foi possível fazer o mapeamento dos problemas, a problematização, construção do parecer ergonômico que sintetiza os problemas observados a partir de sua classificação, seus requisitos, constrangimentos, custos humanos, disfunções do 
sistema culminado com sugestões preliminares de melhoria e restrições. Ressaltou-se problemas de classe movimentacionais, de deslocamento entre grandes distâncias, de acessibilidade, espaciais/arquiteturais de interiores, físicos-ambientais, interfaciais, acidentais, cognitivos e organizacionais. Bem como sugestões preliminares de melhorias.

Com a continuidade da pesquisa pretende-se para além da etapa de apreciação ergonomizadora galgar as etapas da diagnose ergonomizadora, projetação, avaliação, validação e/ou testes, detalhamento ergonômico e otimização.

O trabalho que a UNITI vem desenvolvendo é sem dúvida muito importante para a melhoria de vida e do desenvolvimento dos idosos que ali encontram-se. Entretanto chama-se a atenção para aspectos físicos do ambiente de ensino que foram ignorados resultando assim em barreiras ao público da terceira idade.

\section{REFERÊNCIAS}

ASSOCIAÇÃO BRASILEIRA DE NORMAS TÉCNICAS. NBR 9050: Acessibilidade a edificações, mobiliário, espaços e equipamentos urbanos. Rio de Janeiro: 2004.

NBR 5413: Iluminância de interiores. Rio de Janeiro, 1992.

BRASIL. Lei no 8.842, de 04 de janeiro de 1994. Dispõe sobre a Política Nacional do Idoso, cria o Conselho Nacional do Idoso e dá outras providências.

. Lei no 10.741, de 01 de outubro de 2003. Dispõe sobre o Estatuto do Idoso e dá outras providências.

BRASIL. Lei no 10.098, de 19 de dezembro de 2000. Estabelece normas gerais e critérios básicos para a promoção da acessibilidade das pessoas portadoras de deficiência ou com mobilidade reduzida.

BUSTO ROMERO, Marta Adriana, org. com colab. De Daniel Dresch, Joe Rodrigues.

Reabilitação Ambiental Sustentável Arquitetônica e Urbanística. Brasília: FAU/UnB, p. 429, p. 629, p. 584-587, 2009.

COSTA, Andréa Katiane Ferreira Costa. Preservação do Patrimônio Cultural e Instrumentos para a Promoção de Ações Educativas: O caso de São Luís (1995-2008). Dissertação de Mestrado. Programa de Pós-Graduação em Arquitetura e Urbanismo de Brasília - UnB, p. 51, 2011.

FERREIRA, Aurélio Buarque de Holanda. Miniaurélio Século XXI Escolar: 0

minidicionário da língua portuguesa. Coordenação de edição, Margarida dos Anjos, Marina Baird Ferreira; lexigrafia, Margarida dos Anjos 4 ed. Ver. Ampliada. - Rio de Janeiro: Nova Fronteira, p.38; p. 270, 2001.

FREIRE, Paulo. Pedagogia da autonomia: saberes necessários à prática educativa. São Paulo: Paz e Terra, 1996 (Coleção Leitura), p.22-23;p.81-98.

GOMES FILHO, João. Ergonomia do objeto: sistema técnico de leitura ergonômica. São Paulo: Escrituras Editora, p. 17, p. 205-206, 2003.

IIDA, Itiro. Ergonomia: projeto e produção. São Paulo: Edgar Blucher, p. 139-263, 1992. 
INSTITUTO BRASILEIRO DE GEOGRAFIA E ESTATÍ́STICA. CENSO Demográfico. Perfil dos Idosos Responsáveis pelos Domicílios. Rio de Janeiro. Disponível em:

http://www.ibge.gov.br/home/presidencia/notícias/25072002pidodo.shtm. Acesso em 13.09.2015.

LIMA, Pricilla Melo Ribeiro de; COELHO, Vera Lúcia Decnop. A Arte de Envelhecer: um estudo exploratório sobre a história de vida e o envelhecimento. Artigo publicado em; Psicologia Ciência e Profissão, p. 06-08, 2011.

MORAES, Anamaria de, MONT'ALVÃO, Cláudia. Ergonomia: conceitos e aplicações. Rio de Janeiro:2AB, 2009 (4a edição, ampliada), p. 79-143.

SKINNER, Burrhu Frederic e VAUGHAN, M. E. Viva bem a velhice: aprendendo a programar a sua vida. (Tradução de Anita Liberalesso Neri). São Paulo: Summus, p. 68112, 1985. 